ISSN: 0213-2060

DOI: http://dx.doi.org/10.14201/shhme201634323339

\title{
REDES, PROSOPOGRAFÍA E HISTORIA SOCIAL \\ DE LA ECONOMÍA AL NORTE DE LA CORONA DE CASTILLA EN LA TRANSICIÓN DE LA EDAD MEDIA A LA MODERNA: NOVEDADES HISTORIOGRÁFICAS
}

\author{
Networks, Prosopography and Social History of Economy in the Northern \\ Crown of Castile fromLate Medieval to Early Modern Times: Historiographical \\ Novelties
}

Raúl GONZÁLEZ ARÉVALO

Depto. de Historia Medieval y Ciencias y Técnicas Historiográficas. Facultad de Filosofia y Letras. Universidad de Granada. Campus de la Cartuja. E-18071GRANADA. C. e.: rgonzalezarevalo@ugr.es

Recibido: 2016-06-22

Aceptado: \#\#\#\#-\#\#-\#\#

SUMARIO: 0 Introducción. 1 Redes, prosopografía e historia social de la economía al norte de la Corona de Castilla. 2 Algunas posibilidades para el futuro. 3 Referencias bibliográficas.

\section{INTRODUCCIÓN}

Desde que hace más de cuatro décadas Miguel Ángel Ladero publicara su obra clásica sobrela Hacienda real de Castilla en el siglo xv los estudios sobre fiscalidad y el conocimiento sobre la arquitectura tributaria castellana han cambiado mucho ${ }^{1}$. Probablemente, dos sean los aspectos más visibles de las variaciones introducidas con la entrada del siglo XXI: la

1 Ladero Quesada, Miguel Ángel. La Hacienda real de Castilla en el siglo XV. La Laguna: Secretariado de Publicaciones de la Universidad de La Laguna, 1973 (reeditado en Madrid: Real Academia de la Historia, 2009). 
RAÚL GONZÁLEZ ARÉVALO

REDES, PROSOPOGRAFÍA E HISTORIA SOCIAL DE LA ECONOMÍA AL NORTE DE LA CORONA

documentación empleada y la forma de estudiarla. Efectivamente, frente al predominio casi absoluto del Archivo General de Simancas, y especialmente de sus secciones Contaduría Mayor de Cuentas, $1^{a}$ Época, y Expedientes de Hacienda, el espectro de fuentes se ha ampliado extraordinariamente, con un recurso cada vez mayor a los protocolos notariales y a los registros municipales. La consecuencia directa ha sido que la propia bibliografía ha sufrido un proceso que se podría calificar sin temor a errar de descentralización, pues la perspectiva centralista y estatalista que imponía la información predominante ha ido cediendo espacio de manera progresiva a una óptica en la que predomina la fragmentación que se deriva del estudio de casos concretos, dentro de una lógica territorial específica. Así lo ha puesto de manifiesto el análisis de la estructura y los recursos fiscales en distintos reinos de la Corona, como Galicia, Granada y Toledo, que han sido objeto de sendas Tesis Doctorales específicas en tiempos recientes ${ }^{2}$. Pero también de regiones más o menos definidas, o con algunas características diferenciables frente al resto del territorio castellano, como por ejemplo el País Vasco, la Cornisa Cantábrica o el Valle del Duero.Tampoco se puede olvidar el estudio de instituciones concretas, como la Hermandad General, o de aspectos específicos relacionados con la actividad fiscal, como el crédito y la deuda ${ }^{3}$.

Se trata de una evolución no exenta de tensiones, las clásicas que siempre se dan entre el centro y la periferia, de modo que el estudio del primero no vuelva invisible las peculiaridades específicas de la segunda. En sentido contrario, el abordaje de las segundas siempre ha tenido como condición sine qua non su explicación e inserción dentrodel cuadro y la dinámica general de la Corona. El conocimiento del marco general derivó en un diálogo hasta cierto punto desequilibrado, en el que las realidades locales y regionales no siempre encontraban fiel reflejo en el discurso general, mientras que,en sentido contrario,el recurso al conocimiento general siempre ha servido para realzar las singularidades de casos de estudio específicos. En cualquier caso, la dialéctica entre lo general y lo particular es una constante obligada en el estudio de la materia.

Respecto al modo de trabajo, resulta evidente que a estas alturas la investigación en equipo ha sustituido la tarea antańo solitaria del historiador, de modo que el esfuerzo colectivo permite avanzar más rápido y con una mayor riqueza de perspectivas y metodologías de lo que concedía el trabajo de un único investigador. En este sentido, las publicaciones que sirven como punto de partida para este trabajo resultan muy representativas de lo expuesto, pues son el fruto de dos proyectos de investigación que integran en su núcleo a investigadores en distintos puntos de la carrera académica e investigadora. Me refiero a los proyectos I+D Poder, sociedad y fiscalidad en el entorno geográfico de la Cornisa Cantábrica en el tránsito del Medievo a la Modernidad, dirigido desde la Universidad del País Vasco por Ernesto García Fernández, y Poder, sociedad y fiscalidad entre el Cantábrico

2 Rubio Martínez, Amparo. Hacienda y gobierno de los Reyes Católicos en Galicia. Madrid: Universidad Complutense de Madrid, 2007; Ortega Cera, Ágatha. La fiscalidad regia en el obispado de Granada tras la conquista castellana (1491-1502). Málaga: Universidad de Málaga, 2009; y OrTego Rico, Pablo. Hacienda, poder real y sociedad en Toledo y su Reino (siglo XV-principios del XVI). Madrid: Universidad Complutense de Madrid, 2013.

3 Ladero Quesada, Miguel Ángel. La Hermandad de Castilla. Cuentas y memoriales, 1480-1498. Madrid: Real Academia de la Historia, 2005;Carvajal de la Vega, David. Crédito privado y deuda en Castilla (1480-1521). Valladolid: Universidad de Valladolid, 2013 (Tesis Doctoral inédita). 
RAÚL GONZÁLEZ ARÉVALO

REDES, PROSOPOGRAFÍA E HISTORIA SOCIAL DE LA ECONOMÍA AL NORTE DE LA CORONA DE CASTILLA EN LA TRANSICIÓN DE LA EDAD MEDIA A LA MODERNA: NOVEDADES...

y el Duero en el tránsito del Medievo a la Modernidad, que cuenta con Juan Antonio Bonachía Hernando como investigador principal desde la Universidad de Valladolid. En un ejemplo de cooperación modélico, ambos confluyen a su vez en el proyecto coordinado Poder, sociedad y fiscalidad en la Corona de Castilla: un estudio comparado de la Meseta Norte y de la Cornisa Cantábrica en el tránsito del Medievo a la Modernidad, bajo la dirección conjunta de los dos investigadores citados. Al mismo tiempo, los dos proyectos se integran en otra iniciativa pionera en España, que está teniendo resultados de todo respeto en los últimos años: la red Arca Comunis, con más de una docena de proyectos de distintas universidades españolas, que también se congregan periódicamente en reuniones más o menos temáticas, que encuentran puntual reflejo en sucesivas publicaciones.

Tanto los proyectos de investigación como las publicaciones que patrocinan -en las que, como no podía ser menos, se repiten los nombres de los investigadores-comparten un marco cronológico específico, pues todos están situados generalmente a caballo entre la Edad Media y la Moderna.En consecuencia, el arco cronológico abarcado (1450-1550) rompe sistemáticamente la cesura clásica entre ambos períodos para abarcar de manera coherente el desarrollo de un sistema tributario redefinido durante el reinado de los Reyes Católicos y perfeccionado bajo el de Carlos I. No se trata de una elección casual, pues los cambios en el aparato fiscal y financiero de la Monarquía castellana coincidieron precisamente con un período de crecimiento económico que se extendió, grosso modo, desde mediados del siglo xvhasta mediados de la centuria siguiente. Al mismo tiempo, el volumen documental conservado en el espacio temporal acotado es muy superior al de épocas anteriores, todo lo cual ha desembocado en un campo fértil cuyo conocimiento se renueva constantemente bajo propuestas metodológicas actuales. El resultado final es que se está avanzando con velocidad en un tema cuya imagen de conjunto era bien conocida, pero que estaba lejos de agotar sus posibilidades, como está confirmando el estudio de casos concretos que permiten aún recorridos inéditos, enriqueciendo las perspectivas de un tema que no deja de crecer en complejidad.

\section{Redes, PROSOPOGRAFÍA E HISTORIA SOCIAL DE LA ECONOMÍA AL NORTE} de la Corona de Castilla

La renovación de los estudios sobre fiscalidad castellana se está llevando a cabo de una manera que, hasta cierto punto, se podría calificar de "desorden ordenado». En la“Introducción» al volumen Los negocios del hombre. Comercio y rentas en Castilla. Siglos XV y XVI los editores, Juan Antonio Bonachía y David Carvajal, afirman que el objetivo de la publicación «no fue otro que el de reunir una serie de trabajos que, o bien aportan nuevos datos e informaciones que contribuyen a perfilar con mayor detalle cuestiones planteadas previamente, o bien sirvieran para sugerir la relevancia de otras que hasta ahora han suscitado una menor atención» ${ }^{4}$. Se trata de una descripción

4 Bonachía Hernando, Juan Antonio y Carvajal de la Vega, David. «Introducción». En Bonachía Hernando, Juan Antonio y Carvajal de la Vega, David (eds.).Los negocios del hombre. Comercio y rentas en Castilla. Siglos XV y XVI. Valladolid: Castilla Ediciones, 2012, p. 13. 
RAÚL GONZÁLEZ ARÉVALO

REDES, PROSOPOGRAFÍA E HISTORIA SOCIAL DE LA ECONOMÍA AL NORTE DE LA CORONA DE CASTILLA EN LA TRANSICIÓN DE LA EDAD MEDIA A LA MODERNA: NOVEDADES...

que bien se puede aplicar al resto de publicaciones colectivas que se van a citar, en orden cronológico.

De entrada cabe tener presente que la enorme extensión geográfica de la Corona castellanadesembocaen una enorme diversidad social y económica, lo que hace particularmente complicado cualquier tipo de estudio que aspire a abarcarla en su totalidad. Con frecuencia se observa en la historiografía una cesura entre Mediterráneo y Atlántico, entre el Golfo de Cádiz y el Mar Cantábrico, entre los territorios al norte y al sur del Tajo. Los estudios sobre las realidades financieras y mercantiles no han sido ajenos a este tratamiento. De ahí que no sorprenda el planteamiento geográfico del volumen, que junto al predominio del ámbito vasco -con tres estudios- y de Castilla la Vieja, con centro en Burgos y Valladolid - con otras cuatro contribuciones- ha procurado, sin ánimo de ser exhaustivo ni abarcar todas las posibilidades, ensanchar los horizontes incorporando trabajos particulares sobre otras zonas más «periféricas» como los reinos de Galicia y Granada, La Rioja y Castilla la Nueva. Con ello se cumple un objetivo irrenunciable:recordar que la realidad política de la Corona era una y que, a pesar de todas las variaciones que ofrecen marcos más específicos, es absolutamente necesario reconstruir los nexos entre las realidades mercantiles, financieras y fiscales de los negocios, de modo que muestren las similitudes y diferencias entre los distintos territorios.

En este orden de cosas, es oportuno realizar ejercicios de reflexión, como el que ofrece precisamente el texto de Hilario Casado ${ }^{5}$, que plantea oportunas sugerencias sobre la viabilidad de aplicar la metodología empleada hasta el momento a las grandes redes mercantiles a las redes financieras, y aunque hasta avanzado el siglo XVI no parece haber una conexión directa entre las compañías dedicadas al comercio internacional y las compañías de arrendadores de rentas en Castilla, las semejanzas entre ambas son indudables, incluso a escala territorial. Otro punto indudable de conexión, aunque la autora no insista en ello, lo constituye la formación teórica de los mercaderes castellanos, tema en el que Betsabé Caunedo vuelve a profundizar ${ }^{6}$. Así, junto al aprendizaje básico -leer, escribir, contar- aborda la importancia de la nueva aritmética, formación igualmente esencial para dedicarse al negocio de la renta.

Siguiendo con consideraciones de orden teórico, David Carvajal, tras abordar el proceso de creación de las compañías, profundiza en las diferencias y la caracterización del crédito y el préstamo a través del acceso de mercaderes locales al negocio fiscal mediante la diversificación de las inversiones ${ }^{7}$. La misma estructura se observa en la aportación de Ágatha Ortega, que aborda en primer lugar la dificultad metodológica y documental para estudiar y definir las compañías financieras - partiendo al igual que Hilario Casado de

5 Casado Alonso, Hilario. "Crecimiento económico, redes de comercio y fiscalidad en Castilla a fines de la Edad Media». En Bonachía Hernando y Carvajal de la Vega(eds.),Los negocios del hombre, pp. 17-35.

6 Caunedo del Potro, Betsabé. «Mercaderes castellanos: algunos aspectos de su formación teórica». En Bonachía Hernando y Carvajal de la Vega(eds.), Los negocios del hombre, pp. 37-51.

7 Carvajal de la Vega, David. "Crédito y préstamo entre mercaderes castellanos a fines de la Edad Media». En Bonachía Hernando y Carvajal de la Vega(eds.), Los negocios del hombre, pp. 53-76. Este autor es uno de los principales expertos en las redes socio-económicas del negocio fiscal castellano. 
RAÚL GONZÁLEZ ARÉVALO

REDES, PROSOPOGRAFÍA E HISTORIA SOCIAL DE LA ECONOMÍA AL NORTE DE LA CORONA DE CASTILLA EN LA TRANSICIÓN DE LA EDAD MEDIA A LA MODERNA: NOVEDADES...

la comparación con las compañías mercantiles- para ilustrar su propuesta con el mejor laboratorio de la Corona en tiempos de los Reyes Católicos, el Reino de Granada ${ }^{8}$.

No cabe duda de que el desarrollo de estos estudios depende en gran medida del descubrimiento de nuevas fuentes para su estudio. Así, Iago Irijoa presenta el libro de cuentas de un mercader ońatiarra, contextualizándolo en el ámbito de la villa de Ońati, el retrato biográfico del autor del texto en el seno de su linaje y los aspectos formales del registro. En última instancia ofrece un repaso panorámico por el marco geográfico que abarca, así como sobre las actividades que recoge? .

Eduardo Inclán Gil a partir del comercio exterior vizcaíno retrata el peso adquirido por sus artífices, que adquieren un poder suficiente como para lograr la desvinculación del poderoso Consulado de Burgos y la creación del consulado bilbaíno, autónomo jurídicamente ${ }^{10}$.

El método prosopográfico, nunca citado de forma explícita, es una constante en el estudio de los protagonistas de estas transacciones. Los resultados alcanzan su máximo exponente en la aportación de Ernesto García Fernández, que divide claramente los ejemplos individuales en dos grupos, introducido el primero por consideraciones de corte más teórico y general sobre la génesis y las características de los hombres y mujeres de negocio -muy apreciable porque aún es muy desconocido el elemento de género-. Dedica el segundo bloque a los contadores y tesoreros vascos en la administración de la Corona ${ }^{11}$. Se trata de una estructura que encuentra evidentes paralelismos en el trabajo de Francisco Javier Goicolea Julián, que tras tocar diferentes cuestiones relacionadas con los negocios comerciales y financieros y la participación en el poder de algunos sujetos riojanos, ofrece su aportación más original en la plasmación de la riqueza adquirida en unos modos de vida elitistas ${ }^{12}$.

Entre otras cuestiones, la prosopografía de los protagonistas de las operaciones estudiadas debe traslucir, mediante la aplicación de la sociología de las redes, el complejo sistema de relaciones sociales y económicas indispensable en el desarrollo de los negocios, que permitiera el control y el monopolio de las rentas. Es algo que pone de manifiesto Pablo Ortego al estudiar el arrendamiento de las rentas regias ordinarias castellanas ${ }^{13}$. Se

8 Ortega Cera, Ágatha. «Estrategias, dinero y poder. Compañías financieras castellanas a finales de la Edad Media: una primera propuesta metodológica». En Bonachía Hernando y Carvajal DE LA VEGA(eds.), Los negocios del hombre, pp. 261-286.

9 IrIJOA, Iago. «Fuentes inéditas para el estudio de mercaderes guipuzcoanos a fines de la Edad Media: una aproximación al libro de registros de Juan Ibáńez de Hernani (1495-1503)». En Bonachía HerNANdo y CaRvajal de la Vega(eds.), Los negocios del hombre, pp. 147-173.

10 InClán GiL, Eduardo. «El reconocimiento de la profesionalidad: La consolidación de la ría del Nervión como plataforma del comercio internacional y la puesta en marcha del Consulado de Bilbao (14801525)». En Bonachía Hernando y Carvajal de la Vega(eds.), Los negocios del hombre, pp. 175-200.

11 García Fernández, Ernesto. «Hombres y mujeres de negocios del País Vasco en la Baja Edad Media». En Bonachía Hernando y Carvajal de la Vega(eds.), Los negocios del hombre, pp. 107-146.

12 Goicolea Julián, Javier. «Ciudadanos y mercaderes: hacia una caracterización de los hombres de negocios riojanos a fines de la Edad Media». En Bonachía Hernando y Carvajal de la Vega(eds.), Los negocios del hombre, pp. 77-106.

13 Ortego Rico, Pablo. «Estrategias financieras y especulación en torno al arrendamiento "por mayor” de rentas regias ordinarias en Castilla: aproximación a partir del caso de Castilla la Nueva (1462-1504)». 
trata de un aspecto que también emerge al abordar el encabezamiento de las rentas regias de Valladolid en 1496, estudiado en este caso por Juan Antonio Bonachía, que abre nuevas perspectivas a partir del encabezamiento de las alcabalas de Valladolid y su valor para el estudio de la evolución de la demanda y el consumo en el mercado vallisoletano ${ }^{14}$.

El estudio de las compañías y redes no puede ir aislado del estudio de la familia, estrechamente relacionada en el desarrollo de estrategias de actuación de grupos de poder. Se trata de un aspecto que sugiere otra vía de estudio para poner de manifiesto la estrecha relación entre el fisco y el mercado. Precisamente incide en ello Amparo Rubio desde el ejemplo gallego, a partir de tres ejemplos de auténticos linajes familiares dedicados al comercio y al negocio de la renta, directamente relacionados con grupos de poder oligárquico, de los que llegaron a formar parte ${ }^{15}$.

En definitiva, emerge un esfuerzo muy notable por renovar metodológicamente el panorama de los estudios sobre comercio y rentas en Castilla en la transición de la Edad Media a la Moderna. Así, hay aportaciones que invitan a reflexiones más profundas y otras que, mediante ejemplos concretos, reafirman la necesidad de pasar de lo general a lo particular y viceversa sin solución de continuidad como único modo de abarcar la diversidad regional que albergaba la Corona de Castilla en un marco geográfico, político y económico unitario.

Se puede considerar que este volumen ha tenido una continuidad natural en la obra Hacienda, mercado y poder al norte de la Corona de Castilla en el tránsito del Medievo a la Modernidad ${ }^{16}$. De manera coherente -aunque algo desequilibrada- la publicación se articula en tres grandes bloques temáticos que integran las principales líneas que vertebran la investigación en torno al título. Como aclaran oportunamente los editores en la presentación de la publicación, la primera de ellas está dedicada a mercaderes, comerciantes y banqueros, la segunda a la hacienda regia y la tercera a la hacienda municipal, de forma que se abarcaran los entramados sociales, políticos, económicos, hacendísticos y financieros presentes entre el Duero y el Cantábrico en los siglos XV-XVI, siempre con la intención de realizar una historia economicista en la que los elementos sociales se imponen sobre los puramente económicos, como no podía ser menos habida cuenta que las transferencias fiscales entre contribuyentes y administradores y viceversa tuvieron consecuencias sociales, políticas y económicas desiguales. Precisamente el papel otorgado a la vertiente social de la economía es uno de los puntos fuertes de la óptica adoptada, en un momento en el que no pocos especialistas de Historia económica adscritos a las facultades de Ciencias Económicas del país se inclinan por acotar la disciplina según parámetros

En Bonachía Hernando y Carvajal de la Vega(eds.), Los negocios del hombre, pp. 235-260.

14 Bonachía Hernando, Juan Antonio. «El encabezamiento de alcabalas de Valladolid (1486-1501). Los sistemas de recaudación». En Bonachía Hernando y Carvajal de la Vega(eds.), Los negocios del hombre, pp. 287-321.

15 Rubio Martínez, Amparo. "Mercaderes y financieros en el arrendamiento de rentas reales en la Galicia del siglo xv». En Bonachía Hernando y Carvajal de la Vega(eds.), Los negocios del hombre, pp. 201-233.

16 García Fernández, Ernesto y Bonachía Hernando, Juan Antonio (eds.). Hacienda, mercado y poder al norte de la Corona de Castilla en el tránsito del Medievo a la Modernidad. Valladolid: Castilla Ediciones, 2015. 
RAÚL GONZÁLEZ ARÉVALO

REDES, PROSOPOGRAFÍA E HISTORIA SOCIAL DE LA ECONOMÍA AL NORTE DE LA CORONA DE CASTILLA EN LA TRANSICIÓN DE LA EDAD MEDIA A LA MODERNA: NOVEDADES...

contemporáneos estrictamente económicos, al margen de que semejante perspectiva resulte absurda por la necesidad de adaptar la metodología de estudio para sacar el mayor provecho posible a la naturaleza de las fuentes disponibles. En este sentido, al margen de la cesura que la estructura académica actual impone enla organización de los estudios y los departamentos universitarios, no cabe duda de que las posibilidades ofrecidas por la Historia social de la economía -en total consonancia con la dinámica vigente en la vecina Italia, por ejemplo- constituyen sin duda alguna una ruta obligada para profundizar en este campo. Por otra parte, resulta evidente su conexión con la Historia social del poder, como ha puesto de manifiesto de modo tradicional el matrimonio clásico entre poder político y poder económico.

Así, David Carvajal, tomando en consideración que aún se está profundizando en la formación de la banca y su relación con los financieros y cambiadores, muchas veces ligados al negocio de la renta, estudia a partir de la documentación notarialla consolidación de un grupo de financieros que proveyeron de capital y realizaron labores de intermediación que potenciaron el mercado financiero castellano ${ }^{17}$. Irene Ruiz continúa profundizando en un tema absolutamente descuidado por la historiografía, como es el papel de las mujeres mercaderes y de mercaderes, su relación con las compañías mercantiles y su grado de alfabetización a partir de la misma base documental ${ }^{18}$. Hilario Casado avanza en otro tema olvidado, la presencia castellana y sus negocios en Florencia, en especial por la demanda de lana para los talleres toscanos, a través del estudio específico de la compañía Pesquera-Silos, tomando como punto de partida diversos procesos judiciales de la Chancillería de Valladolid ${ }^{19}$. Mauricio Herrero explica el seguimiento del traspaso de documentos como herramienta para la reconstrucción de trayectorias individuales en archivos externos ${ }^{20}$, mientras que Irene Fiz se ocupa de los temas económicos de la financiación de una obra religiosa en la óptica de la historia social del arte: el monto total y los pagos, con particular atención a los retablos financiados por particulares y los de templos subsidiarios, lejos de las grandes obras y los grandes templos ${ }^{21}$.

El bloque de la Hacienda regia es el que más atención recibe, con ocho trabajos que oscilan entre los que se centran en el estado de la cuestión, matizando hipótesis hasta la fecha aceptadas, y los que cubren lagunas historiográficas desatendidas hasta el momento. Así, Enrique Cantera, partiendo de los datos ofrecidos en su día por el profesor Ladero, busca determinar el papel real de la comunidad hebrea en el arrendamiento de

17 Carvajal de la Vega, David. «En los precedentes de la banca castellana moderna: cambiadores al norte del Tajo a inicios del siglo xvi». En García Fernández y Bonachía Hernando (eds.), Hacienda, mercado y poder, pp. 17-37.

18 Ruiz Albí, Irene. «Mujeres entre mercaderes. La presencia femenina en los protocolos notariales de la provincia de Valladolid en el tránsito del medievo a la modernidad». En García Fernández y Bonachía Hernando (eds.), Hacienda, mercado y poder, pp. 39-67.

19 Casado Alonso, Hilario. «Los negocios de la compañía Pesquera-Silos en Florencia en los inicios del siglo xvi». En García Fernández y Bonachía Hernando (eds.), Hacienda, mercado y poder, pp. 69-97.

20 Herrero Jiménez, Mauricio. «La transferencia de documentos del archivo del mercader Lope de Medina». En García Fernández y Bonachía Hernando (eds.), Hacienda, mercado y poder, pp. 99-118.

21 Fiz Fuertes, Irene. "¿La financiación de un retablo: ¿Quién y cómo se paga?». En García FernáNdez y Bonachía Hernando (eds.), Hacienda, mercado y poder, pp. 119-136. 
RAÚL GONZÁLEZ ARÉVALO

330

REDES, PROSOPOGRAFÍA E HISTORIA SOCIAL DE LA ECONOMÍA AL NORTE DE LA CORONA DE CASTILLA EN LA TRANSICIÓN DE LA EDAD MEDIA A LA MODERNA: NOVEDADES...

rentas, tanto en el número de arrendadores como en el objeto específico de su interés, alcanzando unas extensas conclusiones en las que se mezclan el método prosopográfico y la teoría de redes ${ }^{22}$. Las biografías siguen centrando los estudios de Francisco Javier Goicolea, Ernesto García y Raúl González, en los que se aportan nuevos datos de figuras conocidas parcialmente, sin duda por la dificultad que entraña su estudio y porque la falta de éxito al final de la parábola vital las puede haber hecho menos atractivas ${ }^{23}$.Sin embargo, trascendiendo la mera figura objeto de estudio, todos los autores trazan un retrato mucho más amplio. Así, con Juan de Enciso, Goicolea se centra en la segunda generación de comerciantes y financieros destacados en el siglo xv, de modo que el entramado económico se refuerza con las relaciones personales desarrolladas y afianzadas, hasta copar los puestos más atractivos de la naciente Monarquía Hispánica. Por su parte, García Fernández a partir del contador Pedro Niño traza de modo exhaustivo las cuentas del Principado de Asturias, intercalando en un discurso bien entrelazado los datos políticos, fiscales y financieros. Por último, González analiza el peso de la pertenencia a los círculos de poder cuando cambian los signos políticos a través del ascenso y la caída en desgracia de Juan de Oviedo.

Los siguientes estudios no tienen una temática tan común. Álvaro Aragón incide en la particularidad de la frontera, con exenciones fiscales y aduaneras y el contrabando como mal endémico, lo que enlaza con otras realidades fronterizas castellanas bien conocidas $^{24}$. Por su parte, Alberto Angulo reconstruye una investigación dieciochesca, en la tradición de los eruditos ilustrados, sobre el origen de la aduana de Vitoria y de Orduña ${ }^{25}$. Amparo Rubio aborda la incidencia de la fiscalidad regia y la política económica de la monarquía castellana sobre las diócesis a partir del caso específico de Santiago de Compostela. La conclusión más interesante es la necesidad de la Corona de la colaboración del obispado castellano, apoyo recompensado con la cesión sobre rentas reales ${ }^{26}$. Abundando en la relación entre Iglesia y Estado, cierra el bloque

22 Cantera Montenegro, Enrique. «Los judíos en el arrendamiento de rentas reales en el entorno de la Cornisa Cantábrica: merindades de allende Ebro, Castilla Vieja, Asturias de Santillana, Rioja y Logroño (1406-1474)». En García Fernández y Bonachía Hernando (eds.), Hacienda, mercado y poder, pp. 139-187.

23 Goicolea Julián, Francisco Javier. «De Logroño a la Corte de Carlos V: vida y negocios del contador real Juan de Enciso». En García Fernández y Bonachía Hernando (eds.), Hacienda, mercado y poder, pp. 189-214; García Fernández, Ernesto. «Las cuentas del Principado de Asturias: Hacienda y poder a fines de la Edad Media». En García Fernández y Bonachía Hernando (eds.), Hacienda, mercado y poder, pp. 259-290; GonzÁlez GonzÁlez, Raúl. «Vida, industria y tribulaciones de Juan de Oviedo, recaudador mayor de Asturias (c. 1406-1494)». En García Fernández y Bonachía Hernando (eds.), Hacienda, mercado y poder, pp. 291-323.

24 Aragón Ruano, Álvaro. «Fiscalidad, comercio y frontera en Álava, Guipúzcoa y Navarra entre el siglo xv y la primera mitad del siglo xvi». En García Fernández y Bonachía Hernando (eds.), Hacienda, mercado y poder, pp. 215-239.

25 Angulo Morales, Alberto. «El discurso ilustrado de Floranes. ¿Una primera historia de las aduanas en el País Vasco (siglos XiII-Xvi)?». En García Fernández y Bonachía Hernando (eds.), Hacienda, mercado y poder, pp. 241-258.

26 Rubio Martínez, Amparo. «Iglesia y hacienda regia: la participación de la iglesia compostelana en las rentas de la monarquía a fines del siglo xV». En García Fernández y Bonachía Hernando (eds.), Hacienda, mercado y poder, pp. 325-353. La autora sigue profundizando en el tema de su tesis, al igual que en el trabajo anteriormente citado. Ver supra notas 2 y 15. 
RAÚL GONZÁLEZ ARÉVALO

REDES, PROSOPOGRAFÍA E HISTORIA SOCIAL DE LA ECONOMÍA AL NORTE DE LA CORONA DE CASTILLA EN LA TRANSICIÓN DE LA EDAD MEDIA A LA MODERNA: NOVEDADES...

Francisco Javier Molina, que analiza la conformación y la negociación del patrimonio con documentación monástica que enriquece la imagen oficial de los archivos reales, revelando de qué manera algunas instituciones aprovechaban los recursos de la Corona para sostenerse ${ }^{27}$.

Con el análisis de las haciendas municipales se incide en la diversidad de los sistemas fiscales y financieros de los concejos, lo que amplía la perspectiva regional por las particularidades de los casos y las diferentes situaciones tanto en los ritmos de implantación de la política regia como en el grado de conflictividad política que este proceso generó, si bien las alteraciones parecen haber sido generalizadas. Juan Antonio Bonachía y Maribel del Val, tras un exhaustivo análisis historiográfico y documental, abordan la autonomía de los concejos en materia de gasto a partir del ejemplo vallisoletano, con un excelente análisis de ingresos y gastos en 1497 y $1498^{28}$. María Álvarez plantea de manera novedosa el papel de los vecinos en la conformación del paisaje urbano, con modelos edilicios concretos, entrelazando las identidades urbanas y la conciencia cívica colectiva con el estudio del gasto público en materia de construcción, mantenimiento, reparación y conservación de los edificios ${ }^{29}$. Álvaro Solano aborda la conflictividad social y los mecanismos de participación en el gobierno urbano y el poder concejil en Asturias a través del ejemplo concreto de Villaviciosa ${ }^{30}$. Por último, José Rodríguez Fernández trata desde una perspectiva innovadora la gestión de los recursos hidráulicos como generador de rentas a partir de la percepción del agua como elemento conformador de la organización del territorio ${ }^{31}$.

En definitiva, la obra reviste una gran riqueza y complejidad por la profundidad con la que se abordan temas comunes en un espacio geopolítico unitario en el conjunto de la Corona castellana, y diverso en su articulación interna. El resultado final se constituye en referencia obligada para la materia desde el momento de su publicación por la envergadura de los textos, la novedad de los planteamientos y fuentes utilizadas, lo sugestivo de los resultados y las propuestas para el futuro.

Otro volumen reciente, Hacienda, fiscalidad y agentes económicos en la Cornisa Cantábrica y su entorno (1450-1550). Nuevos textos para su estudio, continúa también otra línea de trabajo abierta en 2012 con la publicación Las Haciendas medievales en el País

27 Molina de la Torre, Francisco Javier. «La documentación monástica como fuente de información fiscal: el caso del monasterio de Santa María la Real de las Huelgas de Valladolid». En García Fernández y Bonachía Hernando (eds.), Hacienda, mercado y poder, pp. 355-376.

28 Bonachía Hernando, Juan Antonio y Val Valdivieso, María Isabel del. «El sistema fiscal y financiero del concejo de Valladolid». En García Fernández y Bonachía Hernando (eds.), Hacienda, mercado y poder, pp. 379-436.

29 Álvarez Fernández, María. «Proyectos urbanos y políticas financieras para una ciudad moderna. Tradición e innovación en Oviedo (siglos Xv-Xvi)». En García Fernández y Bonachía Hernando (eds.), Hacienda, mercado y poder, pp. 437-468.

30 Solano Fernández-Sordo, Álvaro. "Algunas cosas que son neçesarias para la buena governaçión de dicha villa e conçejo. Poder concejil, gobierno urbano y conflicto social en Villaviciosa a fines de la Edad Media». En García Fernández y Bonachía Hernando (eds.), Hacienda, mercado y poder, pp. 469-499.

31 Rodríguez FERnÁNDEZ, José. «Los señores del agua en el entorno urbano alavés bajomedieval: monarquía, élites urbanas y poder concejil en torno al control de los recursos hídricos». En García FERnáNDEZ y Bonachía Hernando (eds.), Hacienda, mercado y poder, pp. 501-527. 
RAÚL GONZÁLEZ ARÉVALO

332

REDES, PROSOPOGRAFÍA E HISTORIA SOCIAL DE LA ECONOMÍA AL NORTE DE LA CORONA DE CASTILLA EN LA TRANSICIÓN DE LA EDAD MEDIA A LA MODERNA: NOVEDADES...

Vasco y La Rioja. Textos para su estudio. ${ }^{32}$ Siguiendo su modelo e incorporando al marco de estudio Cantabria, Asturias y Galicia, la presente obra supera de largo la mera edición de fuentes con la inclusión de cuatro estudios, además de la extensa y certera presentación de Ernesto García. La transcripción de 70 textos escogidos, en su mayoría inéditos, reflejan la tipología documental diversa: cartas de merced, juros de heredad, cartas de recudimiento, sentencias judiciales, derramas o repartimientos del pedido, encabezamientos de alcabalas, arrendamientos de rentas concejiles y libros de cuentas para el estudio de las haciendas municipales, provinciales y regia. Todos han servido de base para las cuatro disertaciones que los presentan, aunque no agotan sus posibilidades, dado que las ópticas y metodologías son tantas como investigaciones se llevan a cabo sobre ellas.

Como recoge excelentemente Ernesto García en su presentación, entre las materias abordadas en todos los estudios que integran la obra cabe destacar varias, a saber: la relación entre poder, hacienda y mercados; la administración de las haciendas locales; las élites financieras de los ámbitos local y territorial; el papel de los comerciantes en la vida económica entendida en un sentido integrador más amplio; y el lugar que los agentes económicos ocuparon en la sociedad de la región cantábrica de mediados del siglo XV a mediados del XVI. El estudio de estos agentes fiscales es de primera importancia de cara a profundizar en el conocimiento de los sistemas hacendísticos, teniendo en cuenta que la maquinaria fiscal y financiera de los distintos niveles de la administración dependía en buena medida de ellos ${ }^{33}$. En definitiva, los cuatro estudios tienen en común -entre sí pero tambiéncon las publicaciones anteriores, cabe ańadir- que ponen el acento en la relación ciertamente estrecha entre el poder, la hacienda y los mercados en sus niveles central -la Corona-, regional -comarcas y reinos- y local -los núcleos urbanos-. En todos los planos los agentes económicos principales son mercaderes, financieros y juristas. $\mathrm{Al}$ mismo tiempo, la relación entre todas las administraciones obliga a ir constantemente de lo general a lo particular y viceversa en un discurso en el que la flexibilidad es la tónica dominante, tanto en el desarrollo de la exposición como en la metodología aplicada, que por fuerza tiene que adaptarse a las especificidades comarcales y territoriales de cada caso de estudio. Además, cabe tener presente que las transformaciones operadas en las haciendas castellanas en un arco temporal tan amplio no fueron las mismas en todos los espacios, como tampoco fue homogéneo el ritmo de implantación de las directrices de la Corona. De la misma manera, el peso de la Iglesia en Galicia introduce un nuevo elemento en las estructuras hacendísticas del noroeste peninsular que lo diferencia netamente del resto de la Cornisa Cantábrica.

Imanol Vítores centra su contribución en el diseño del sistema fiscal en estas regiones periféricas, presentando sus características generales, para lo que pasa de las directrices

32 García Fernández, Ernesto y Goicolea Julián, Francisco Javier (coords.). Las haciendas medievales en el País Vasco y La Rioja. Textos para su estudio. Madrid: Instituto de Estudios Fiscales, 2012; Vítores Casado, Imanol; Goicolea Julián, Francisco Javier;Angulo Morales, Alberto y Aragón Ruano, Álvaro (eds.). Hacienda, fiscalidad y agentes económicos en la Cornisa Cantábrica y su entorno (1450-1550). Nuevos textos para su estudio. Bilbao: Universidad del País Vasco, 2015.

33 García Fernández, Ernesto. «Presentación. La Cornisa Cantábrica entre los siglos xv y Xvi: en la periferia de los centros de poder político de la monarquía castellana». En Vítores Casado, Goicolea Julián, Angulo Morales y Aragón Ruano (eds.),Hacienda, fiscalidad y agentes económicos, pp. 9-27. 
RAÚL GONZÁLEZ ARÉVALO

REDES, PROSOPOGRAFÍA E HISTORIA SOCIAL DE LA ECONOMÍA AL NORTE DE LA CORONA DE CASTILLA EN LA TRANSICIÓN DE LA EDAD MEDIA A LA MODERNA: NOVEDADES...

de la Corona a las Juntas Generales y las haciendas municipales, que constituyen los tres grandes bloques en los que articula su discurso, en contacto permanente con el mercado, la economía local y las relaciones sociopolíticas que constituyen el cuadro en el que se insertan ${ }^{34}$.

El estudio de Francisco Javier Goicolea es el menos extenso en su marco geográfico, pues abarca la gestión de los ingresos y los gastos ordinarios de los concejos de La Rioja y Álava.En primer lugar señala la insuficiencia de los recursos fiscales ordinarios para hacer frente a los gastos corrientes, lo que obligó a generar recursos extraordinarios. En segundo lugar,determinacómo la implantación de los encabezamientos de alcabalas en el territorio tuvo enormes consecuencias en estas haciendas municipales ${ }^{35}$.

Álvaro Aragón insiste de nuevo en el hecho diferencial fronterizo, es decir, cómo la realidad limítrofe del mar y de otros reinos -Navarra, Aragón- fue un argumento preferente en la estrategia de las élites locales para la obtención de privilegios de la Corona. En una óptica cercana al método prosopográfico, repasa las principales familias que destacaron en los núcleos urbanos cantábricos, todas estrechamente relacionadas con el comercio y presentes en los gobiernos fiscales y el negocio de la renta, en una fusión clásica entre oligarquía ciudadana y economía local que aprovechaba en este caso concreto la posición estratégica de los territorios y la debilidad de la Corona para monopolizar e incluso patrimonializar los cargos concejiles, siempre utilizados en provecho propio. Semejante planteamiento se inserta en la lógica que concebía estas actividades como trampolín para acceder a otras instancias superiores, en último lugar la Corte ${ }^{36}$.

Por último, Alberto Angulo trasciende el marco geográfico estrictamente cantábrico al recurrir al examen de las comunidades «vizcaínas» fuera del País Vasco, en Sevilla, Huesca, Valencia e incluso fuera de la Península, en Brujas y Amberes, como observatorios externos. En ellas sus miembros se organizaban habitualmente como cofradía -o nación en los Países Bajos- en las que se fortalecían las relaciones y los intereses comunes, base para el desarrollo de negocios, incluyendo el de la renta ${ }^{37}$.

Como apunta el profesor García Fernández en su introducción, se trata de primeros resultados que no agotan el tema, proponiendo para el futuro numerosas líneas de investigación. Y lo mismo cabe decir de la última publicación que cierra este recorrido por las novedades historiográficas sobre la historia social de la economía. El regesto de más de 7.000 documentos sobre mercaderes y cambiadores presentes en los protocolos notariales

34 Vítores Casado, Imanol. «Poder, hacienda y mercados en la Cornisa Cantábrica a fines de la Edad Media: balances y perspectivas para una visión de conjunto». En Vítores Casado, Goicolea Julián, Angulo Morales y Aragón Ruano (eds.), Hacienda, fiscalidad y agentes económicos, pp.31-55.

35 Goicolea Julián, Francisco Javier. «La gestión local del negocio fiscal en territorios del interior: de las merindades riojanas a tierras alavesas (1450-1550)». En Vítores Casado, Goicolea Julián, Angulo Morales y Aragón Ruano (eds.), Hacienda, fiscalidad y agentes económicos, pp. 57-102.

36 Aragón Ruano, Álvaro. "De la administración financiera local y provincial a la Corte. Élites financieras al norte del Ebro a comienzos de la Edad Moderna». En Vítores Casado, Goicolea Julián, Angulo Morales y Aragón Ruano (eds.), Hacienda, fiscalidad y agentes económicos, pp.103-137.

37 Angulo Morales, Alberto. «Criaderos de agentes económicos. Las colonias mercantiles vascas en los inicios de la Edad Moderna (1450-1550)». En Vítores Casado, Goicolea Julián, Angulo Morales y Aragón Ruano (eds.), Hacienda, fiscalidad y agentes económicos, pp. 139-175. 
RAÚL GONZÁLEZ ARÉVALO

REDES, PROSOPOGRAFÍA E HISTORIA SOCIAL DE LA ECONOMÍA AL NORTE DE LA CORONA

de Medina de Rioseco, Medina del Campo, Valladolid y Tordesillas en poco más de tres décadas (1486-1520) ofrece unas posibilidades insospechadas, por no decir infinitas, para la historia social de la economía ${ }^{38}$. El índice onomástico, el listado de mercaderes y cambiadores por lugar de vecindad en Espańa y el listado de mercaderes y cambiadores extranjeros facilitan -como la inclusión de un CD-ROM- las búsquedas para los investigadores. La introducción se realiza a partir de tres estudios dedicados a "Localidades, escribanos públicos y protocolos notariales», donde los datos reinan por encima de las consideraciones puramente diplomáticas; «Tipología documental», que distingue en su análisis entre las cartas de los negocios particulares y losdocumentos procesales; y por último «Mercaderes y cambiadores en los registros notariales vallisoletanos», el estudio histórico introductorio propiamente dicho. El predominio de los agentes económicos del norte de la Corona castellana es abrumador, como ya se intuía por otra parte.

No quisiera finalizar este recorrido historiográfico sin una breve reflexión que surgía recurrente en las lecturas. Así, resulta llamativo que en todo el análisis referido hasta el momento, en el que destaca el estudio de colectivos como cambiadores, mujeres, compañías, redes financieras y mercantiles, agentes, comunidades extranjeras o minorías sociales como los judíos, no haya referencias al papel que desempeña el método prosopográfico -entendido como el estudio de un segmento concreto de la población, fácilmente identificable en una serie de aspectos que comparten sus miembros- frente al papel otorgado a la teoría de redes, tan en boga en los últimos años. Sin duda las redes son fundamentales para situar geográfica, espacial, social y económicamente los sujetos de estudio, pero sin la conveniente delimitación o justificación del sujeto histórico social -precisamente la parte que corresponde a la prosopografía- se corre el riesgo de desnaturalizar el marco que les da cobijo. Afortunadamente no es el caso en ninguno de los volúmenes analizados.

\section{Algunas posibilidades para el Futuro}

Para cerrar este texto quisiera proponer algunas posibilidades de estudio que las lecturas recogidas me han sugerido. Siguiendo con la descentralización en el análisis del entramado fiscal castellano, sería conveniente prestar atención a la variante que ofrecen los señoríos nobiliarios, comopor ejemplo el de los Velasco, Condestables de Castilla, en tierras cántabras.La bibliografía en este sentido no es reducida, pero sería conveniente incorporar las nuevas fuentes y las últimas tendencias historiográficas ${ }^{39}$. De la misma

38 Carvajal de la Vega, David;Herrero Jiménez, Mauricio;Molina de la Torre, Francisco J. yRuiz Albí, Irene. Mercaderes y cambiadores en los protocolos notariales de la provincia de Valladolid (14861520). Valladolid: Ediciones Universidad de Valladolid, 2015.

39 Sin ánimo de ser exhaustivo quiero recordar aquí la obra de Martínez Moro, Jesús. La renta feudal en la Castilla del siglo XV: los Stúñigas. Valladolid: Ediciones Universidad de Valladolid, 1977. Concepción Quintanilla ha dedicado algunos estudios y ha realizado propuestas metodológicas aún vigentes. Cf. Quintanilla Raso, María Concepción. «Haciendas señoriales nobiliarias en el reino de Castilla a fines de la Edad Media». En Historia de la Hacienda Española. Épocas antigua y medieval. Homenaje a Luis García de Valdeavellano. Madrid: Instituto de Estudios Fiscales, 1982, pp. 767-798; de esta misma autora en el ámbito andaluz también sirvede ejemplo «Haciendas señoriales andaluzas a fines de la Edad Media». En II Coloquio 
RAÚL GONZÁLEZ ARÉVALO

REDES, PROSOPOGRAFÍA E HISTORIA SOCIAL DE LA ECONOMÍA AL NORTE DE LA CORONA DE CASTILLA EN LA TRANSICIÓN DE LA EDAD MEDIA A LA MODERNA: NOVEDADES...

manera, teniendo en cuenta la presencia de comunidades mudéjares en el norte de la Corona castellana, habría que insistir en el conocimiento de la fiscalidad diferencial de la que eran objeto en territorios como los obispados de Burgos, Palencia, Osma, Calahorra o Sigüenza, sobre todo a la luz de las posibilidades que la documentación simanquina reveló en su día para el Reino de Granada ${ }^{40}$.

En los estudios que se han analizado la fiscalidad eclesiástica ha tenido un espacio muy reducido, salvo por dos ejemplos muy llamativos, el arzobispado de Santiago y el Monasterio de Las Huelgas de Valladolid. Indudablemente los datos aportados por los autores, la imbricación en la arquitectura fiscal del reino y el apoyo de la Corona en la Iglesia para temas fiscales hacen obligado continuar por esta senda, sin olvidar los datos que pueden aportar también en términos de producción agraria ${ }^{41}$. De la misma manera que la publicación de fuentes documentales -y se han traído aquí dos volúmenes- resulta indispensable para hacer más accesible a los investigadores la tarea ingente que queda por delante, si bien los libros de cuentas municipales están a la cabeza por el interés que reviste el tema y la atención reducida que la fiscalidad concejil ha recibido en comparación con la regia ${ }^{42}$.

En definitiva, las escasas propuestas humildemente esbozadas no hacen sino insistir, de una parte, en la necesidad de desarrollar aspectos recogidos por los volúmenes abordados - como la fiscalidad municipal y eclesiástica, la edición de fuentes- y, de otra, recordar temas clásicos -fiscalidad señorial y mudéjar- que no han encontrado hueco aún en esta renovación historiográfica que está experimentando el estudio de la historia social de la economía al norte de la Corona de Castilla.

\section{REFERENCIAS BIBLIOGRÁfICAS}

Álvarez Fernández, María. «Proyectos urbanos y políticas financieras para una ciudad moderna. Tradición e innovación en Oviedo (siglos XV-XVI)». En García Fernández, Ernesto y BonaChía Hernando, Juan Antonio (eds.). Hacienda, mercado y poder al norte de la Corona de Castilla en el tránsito del Medievo a la Modernidad. Valladolid: Castilla Ediciones, 2015, pp. 437-468.

de Historia Medieval Andaluza. Sevilla: Diputación Provincial de Sevilla, 1982, pp. 53-65. Más recientemente, con amplia bibliografía, se puede citar el trabajo de López Sabatel, José Antonio. "Rentas y exigencias feudales en la tierra de Lemos durante la Baja Edad Media (siglos XIV-Xv)». Anuario de Estudios Medievales, 2011, vol. 41, n. ${ }^{\circ} 1$,pp. 211-234.

40 Imposible no citar los estudios clásicos del profesor Ladero: LADERo Quesada, Miguel Ángel. Los mudéjares de Castilla en tiempo de Isabel I. Valladolid: Instituto Isabel la Católica de Historia Eclesiástica, 1969; «Los mudéjares de Castilla en la Baja Edad Media». Historia. Instituciones. Documentos, 1975, vol. 5, pp. 257-304; y la puesta al día en «Los mudéjares de Castilla cuarenta años después». En la España Medieval, 2010, vol. 33, pp. 383-424. Para fiscalidad y moriscos en el reino granadino inmediatamente después de la conversión general de los mudéjares cf. Galán Sánchez, Ángel y Peinado Santaella, Rafael G.Hacienda regia y población en el Reino de Granada: la geografía morisca a comienzos del siglo XVI. Granada: Universidad de Granada, 1997.

41 Cabe recordar aquí la obra de Ladero Quesada, Miguel Ángel y GonZÁlez Jiménez, Manuel. Diezmo eclesiástico y producción de cereales en el reino de Sevilla (1503-1508). Sevilla: Universidad de Sevilla, 1978.

42 En este sentido quiero llamar la atención sobre la reciente publicación de Moreno Trujillo, M.a Amparo;Obra Sierra, Juan M. a de la y Osorio Pérez, M. a José. Los libros de rentas municipales de la ciudad de Granada en el siglo XVI. Granada: Editorial Universidad de Granada, 2015. 
RAÚL GONZÁLEZ ARÉVALO

336

REDES, PROSOPOGRAFÍA E HISTORIA SOCIAL DE LA ECONOMÍA AL NORTE DE LA CORONA DE CASTILLA EN LA TRANSICIÓN DE LA EDAD MEDIA A LA MODERNA: NOVEDADES...

Angulo Morales, Alberto. «Criaderos de agentes económicos. Las colonias mercantiles vascas en los inicios de la Edad Moderna (1450-1550)». En Vítores CASAdo, Imanol; Goicolea Julián, Francisco Javier;Angulo Morales, Alberto y Aragón Ruano, Álvaro (eds.). Hacienda, fiscalidad y agentes económicos en la Cornisa Cantábrica y su entorno (1450-1550). Nuevos textos para su estudio. Bilbao: Universidad del País Vasco, 2015, pp. 139-175.

Angulo Morales, Alberto. «El discurso ilustrado de Floranes. ¿Una primera historia de las aduanas en el País Vasco (siglos XiII-XVi)?». En García Fernández, Ernesto y Bonachía HerNAndo, Juan Antonio (eds.). Hacienda, mercado y poder al norte de la Corona de Castilla en el tránsito del Medievo a la Modernidad. Valladolid: Castilla Ediciones, 2015, pp. 241-258.

Aragón RuAno, Álvaro. «De la administración financiera local y provincial a la Corte. Élites financieras al norte del Ebro a comienzos de la Edad Moderna». En VÍtores CASAdo, Imanol; Goicolea Julián, Francisco Javier;Angulo Morales, Alberto y Aragón Ruano, Álvaro (eds.). Hacienda, fiscalidad y agentes económicos en la Cornisa Cantábrica y su entorno (14501550). Nuevos textos para su estudio. Bilbao: Universidad del País Vasco, 2015, pp.103-137.

Aragón Ruano, Álvaro. «Fiscalidad, comercio y frontera en Álava, Guipúzcoa y Navarra entre el siglo xv y la primera mitad del siglo xvI». En García Fernández, Ernesto y Bonachía Hernando, Juan Antonio (eds.). Hacienda, mercado y poder al norte de la Corona de Castilla en el tránsito del Medievo a la Modernidad. Valladolid: Castilla Ediciones, 2015, pp. 215-239.

Bonachía Hernando, Juan Antonio y Carvajal de la Vega, David. «Introducción». En Bonachía Hernando, Juan Antonio y Carvajal de la Vega, David (eds.).Los negocios del hombre. Comercio y rentas en Castilla. Siglos XV y XVI. Valladolid: Castilla Ediciones, 2012.

Bonachía Hernando, Juan Antonio y Val Valdivieso, María Isabel del. «El sistema fiscal y financiero del concejo de Valladolid». En García Fernández, Ernesto y Bonachía HerNANDo, Juan Antonio (eds.). Hacienda, mercado y poder al norte de la Corona de Castilla en el tránsito del Medievo a la Modernidad. Valladolid: Castilla Ediciones, 2015, pp. 379-436.

Bonachía Hernando, Juan Antonio. «El encabezamiento de alcabalas de Valladolid (14861501). Los sistemas de recaudación». En Bonachía Hernando, Juan Antonio y Carvajal DE la VeGa, David (eds.).Los negocios del hombre. Comercio y rentas en Castilla. Siglos XV y XVI. Valladolid: Castilla Ediciones, 2012, pp. 287-321.

Cantera Montenegro, Enrique. «Los judíos en el arrendamiento de rentas reales en el entorno de la Cornisa Cantábrica: merindades de allende Ebro, Castilla Vieja, Asturias de Santillana, Rioja y Logroño (1406-1474)». En García Fernández, Ernesto y Bonachía Hernando, Juan Antonio (eds.). Hacienda, mercado y poder al norte de la Corona de Castilla en el tránsito del Medievo a la Modernidad. Valladolid: Castilla Ediciones, 2015, pp. 139-187.

Carvajal de la Vega, David. «Crédito y préstamo entre mercaderes castellanos a fines de la Edad Media». En Bonachía Hernando, Juan Antonio y Carvajal de la Vega, David (eds.).Los negocios del hombre. Comercio y rentas en Castilla. Siglos XV y XVI. Valladolid: Castilla Ediciones, 2012, pp. 53-76.

Carvajal de la Vega, David. «En los precedentes de la banca castellana moderna: cambiadores al norte del Tajo a inicios del siglo Xvi». En García Fernández, Ernesto y Bonachía HerNANDo, Juan Antonio (eds.). Hacienda, mercado y poder al norte de la Corona de Castilla en el tránsito del Medievo a la Modernidad. Valladolid: Castilla Ediciones, 2015, pp. 17-37.

Carvajal de la Vega, David. Crédito privado y deuda en Castilla (1480-1521). Valladolid: Universidad de Valladolid, 2013 (Tesis Doctoral inédita).

Carvajal de la Vega, David;Herrero Jiménez, Mauricio;Molina de la Torre, Francisco J. yRuiz Albí, Irene. Mercaderes y cambiadores en los protocolos notariales de la provincia de Valladolid (1486-1520). Valladolid: Ediciones Universidad de Valladolid, 2015. 
RAÚL GONZÁLEZ ARÉVALO

REDES, PROSOPOGRAFÍA E HISTORIA SOCIAL DE LA ECONOMÍA AL NORTE DE LA CORONA DE CASTILLA EN LA TRANSICIÓN DE LA EDAD MEDIA A LA MODERNA: NOVEDADES...

Casado Alonso, Hilario. "Crecimiento económico, redes de comercio y fiscalidad en Castilla a fines de la Edad Media». En Bonachía Hernando, Juan Antonio y Carvajal de la Vega, David (eds.).Los negocios del hombre. Comercio y rentas en Castilla. Siglos XV y XVI. Valladolid: Castilla Ediciones, 2012, pp. 17-35.

Casado Alonso, Hilario. «Los negocios de la compañía Pesquera-Silos en Florencia en los inicios del siglo xvi». En García Fernández y Bonachía Hernando (eds.), Hacienda, mercado y poder, pp. 69-97.

Caunedo del Potro, Betsabé. «Mercaderes castellanos: algunos aspectos de su formación teórica». En Bonachía Hernando, Juan Antonio y Carvajal de la Vega, David (eds.).Los negocios del hombre. Comercio y rentas en Castilla. Siglos XV y XVI. Valladolid: Castilla Ediciones, 2012, pp. 37-51.

Fiz Fuertes, Irene. «¿La financiación de un retablo: ¿Quién y cómo se paga?». En García FernÁndeZ, Ernesto y Bonachía Hernando, Juan Antonio (eds.). Hacienda, mercado y poder al norte de la Corona de Castilla en el tránsito del Medievo a la Modernidad. Valladolid: Castilla Ediciones, 2015, pp. 119-136.

Galán Sánchez, Ángel y Peinado Santaella, Rafael G.Hacienda regia y población en el Reino de Granada: la geografía morisca a comienzos del siglo XVI. Granada: Universidad de Granada, 1997.

García Fernández, Ernesto y Bonachía Hernando, Juan Antonio (eds.). Hacienda, mercado y poder al norte de la Corona de Castilla en el tránsito del Medievo a la Modernidad. Valladolid: Castilla Ediciones, 2015.

García Fernández, Ernesto y Goicolea Julián, Francisco Javier (coords.). Las haciendas medievales en el País Vasco y La Rioja. Textos para su estudio. Madrid: Instituto de Estudios Fiscales, 2012.

García Fernández, Ernesto. «Hombres y mujeres de negocios del País Vasco en la Baja Edad Media». En Bonachía Hernando, Juan Antonio y Carvajal de la Vega, David (eds.).Los negocios del hombre. Comercio y rentas en Castilla. Siglos XV y XVI. Valladolid: Castilla Ediciones, 2012, pp. 107-146.

García Fernández, Ernesto. "Las cuentas del Principado de Asturias: Hacienda y poder a fines de la Edad Media». En García Fernández, Ernesto y Bonachía Hernando, Juan Antonio (eds.). Hacienda, mercado y poder al norte de la Corona de Castilla en el tránsito del Medievo a la Modernidad. Valladolid: Castilla Ediciones, 2015, pp. 259-290.

García Fernández, Ernesto. «Presentación. La Cornisa Cantábrica entre los siglos xv y xvi: en la periferia de los centros de poder político de la monarquía castellana». En Vítores Casado, Imanol; Goicolea Julián, Francisco Javier;Angulo Morales, Alberto y Aragón Ruano, Álvaro (eds.). Hacienda, fiscalidad y agentes económicos en la Cornisa Cantábrica y su entorno (1450-1550). Nuevos textos para su estudio. Bilbao: Universidad del País Vasco, 2015, pp. 9-27.

Goicolea Julián, Francisco Javier. «De Logroño a la Corte de Carlos V: vida y negocios del contador real Juan de Enciso». En García Fernández, Ernesto y Bonachía Hernando, Juan Antonio (eds.). Hacienda, mercado y poder al norte de la Corona de Castilla en el tránsito del Medievo a la Modernidad. Valladolid: Castilla Ediciones, 2015, pp. 189-214.

Goicolea Julián, Francisco Javier. «La gestión local del negocio fiscal en territorios del interior: de las merindades riojanas a tierras alavesas (1450-1550)». En Vítoroses Casado, Imanol; Goicolea Julián, Francisco Javier;Angulo Morales, Alberto y Aragón Ruano, Álvaro (eds.). Hacienda, fiscalidad y agentes económicos en la Cornisa Cantábrica y su entorno (14501550). Nuevos textos para su estudio. Bilbao: Universidad del País Vasco, 2015, pp. 57-102.

Goicolea Julián, Javier. «Ciudadanos y mercaderes: hacia una caracterización de los hombres de negocios riojanos a fines de la Edad Media». En Bonachía Hernando, Juan Antonio 
RAÚL GONZÁLEZ ARÉVALO

REDES, PROSOPOGRAFÍA E HISTORIA SOCIAL DE LA ECONOMÍA AL NORTE DE LA CORONA DE CASTILLA EN LA TRANSICIÓN DE LA EDAD MEDIA A LA MODERNA: NOVEDADES...

y Carvajal de la Vega, David (eds.).Los negocios del hombre. Comercio y rentas en Castilla. Siglos XV y XVI. Valladolid: Castilla Ediciones, 2012, pp. 77-106.

GonzÁlez GonzÁLEZ, Raúl. «Vida, industria y tribulaciones de Juan de Oviedo, recaudador mayor de Asturias (c. 1406-1494)». En García Fernández, Ernesto y Bonachía Hernando, Juan Antonio (eds.). Hacienda, mercado y poder al norte de la Corona de Castilla en el tránsito del Medievo a la Modernidad. Valladolid: Castilla Ediciones, 2015, pp. 291-323.

Herrero JimÉnez, Mauricio. «La transferencia de documentos del archivo del mercader Lope de Medina». En García Fernández, Ernesto y Bonachía Hernando, Juan Antonio (eds.). Hacienda, mercado y poder al norte de la Corona de Castilla en el tránsito del Medievo a la Modernidad. Valladolid: Castilla Ediciones, 2015, pp. 99-118.

INCLÁN GIL, Eduardo. «El reconocimiento de la profesionalidad: La consolidación de la ría del Nervión como plataforma del comercio internacional y la puesta en marcha del Consulado de Bilbao (1480-1525)». En Bonachía Hernando, Juan Antonio y Carvajal de la Vega, David (eds.).Los negocios del hombre. Comercio y rentas en Castilla. Siglos XV y XVI. Valladolid: Castilla Ediciones, 2012, pp. 175-200.

IRIJOA, Iago. «Fuentes inéditas para el estudio de mercaderes guipuzcoanos a fines de la Edad Media: una aproximación al libro de registros de Juan Ibáñez de Hernani (1495-1503)». En BonAchía Hernando, Juan Antonio y Carvajal de la Vega, David (eds.).Los negocios del hombre. Comercio y rentas en Castilla. Siglos XV y XVI. Valladolid: Castilla Ediciones, 2012, pp. 147-173.

Ladero Quesada, Miguel Ángel y González Jiménez, Manuel. Diezmo eclesiástico y producción de cereales en el reino de Sevilla (1503-1508). Sevilla: Universidad de Sevilla, 1978.

Ladero Quesada, Miguel Ángel. «Los mudéjares de Castilla cuarenta años después». En la España Medieval, 2010, vol. 33, pp. 383-424.

Ladero Quesada, Miguel Ángel. «Los mudéjares de Castilla en la Baja Edad Media». Historia. Instituciones. Documentos, 1975, vol. 5, pp. 257-304.

Ladero Quesada, Miguel Ángel. La Hacienda real de Castilla en el siglo XV. La Laguna: Secretariado de Publicaciones de la Universidad de La Laguna, 1973.

Ladero Quesada, Miguel Ángel. La Hermandad de Castilla. Cuentas y memoriales, 1480-1498. Madrid: Real Academia de la Historia, 2005.

Ladero Quesada, Miguel Ángel. Los mudéjares de Castilla en tiempo de Isabel I. Valladolid: Instituto Isabel la Católica de Historia Eclesiástica, 1969.

López Sabatel, José Antonio. «Rentas y exigencias feudales en la tierra de Lemos durante la Baja Edad Media (siglos xIV-xv)». Anuario de Estudios Medievales, 2011, vol. 41, n. ${ }^{\circ}$ 1, pp. 211-234.

Martínez Moro, Jesús. La renta feudal en la Castilla del siglo XV: los Stúnigas. Valladolid: Ediciones Universidad de Valladolid, 1977.

Molina DE LA TORRe, Francisco Javier. «La documentación monástica como fuente de información fiscal: el caso del monasterio de Santa María la Real de las Huelgas de Valladolid». En García Fernández, Ernesto y Bonachía Hernando, Juan Antonio (eds.). Hacienda, mercado y poder al norte de la Corona de Castilla en el tránsito del Medievo a la Modernidad. Valladolid: Castilla Ediciones, 2015, pp. 355-376.

Moreno Trujillo, M. a Amparo;Obra Sierra, Juan M. a de la y Osorio Pérez, M. ${ }^{a}$ José. Los libros de rentas municipales de la ciudad de Granada en el siglo XVI. Granada: Editorial Universidad de Granada, 2015.

Ortega Cera, Ágatha. «Estrategias, dinero y poder. Compañías financieras castellanas a finales de la Edad Media: una primera propuesta metodológica». En Bonachía Hernando, Juan Antonio y Carvajal de la Vega, David (eds.).Los negocios del hombre. Comercio y rentas en Castilla. Siglos XV y XVI. Valladolid: Castilla Ediciones, 2012, pp. 261-286. 
RAÚL GONZÁLEZ ARÉVALO

REDES, PROSOPOGRAFÍA E HISTORIA SOCIAL DE LA ECONOMÍA AL NORTE DE LA CORONA DE CASTILLA EN LA TRANSICIÓN DE LA EDAD MEDIA A LA MODERNA: NOVEDADES...

Ortega Cera, Ágatha. La fiscalidad regia en el obispado de Granada tras la conquista castellana (1491-1502). Málaga: Universidad de Málaga, 2009.

Ortego Rico, Pablo. «Estrategias financieras y especulación en torno al arrendamiento "por mayor" de rentas regias ordinarias en Castilla: aproximación a partir del caso de Castilla la Nueva (1462-1504)». En Bonachía Hernando, Juan Antonio y Carvajal de la Vega, David (eds.).Los negocios del hombre. Comercio y rentas en Castilla. Siglos XV y XVI. Valladolid: Castilla Ediciones, 2012, pp. 235-260.

Ortego Rico, Pablo. Hacienda, poder real y sociedad en Toledo y su Reino (siglo XV-principios del XVI). Madrid: Universidad Complutense de Madrid, 2013.

Quintanilla Raso, María Concepción. "Haciendas señoriales andaluzas a fines de la Edad Media». En II Coloquio de Historia Medieval Andaluza. Sevilla: Diputación Provincial de Sevilla, 1982, pp. 53-65.

Quintanilla Raso, María Concepción. «Haciendas señoriales nobiliarias en el reino de Castilla a fines de la Edad Media». En Historia de la Hacienda Española. Épocas antigua y medieval. Homenaje a Luis García de Valdeavellano. Madrid: Instituto de Estudios Fiscales, 1982, pp. 767-798.

Rodríguez FERnÁNDEZ, José. «Los señores del agua en el entorno urbano alavés bajomedieval: monarquía, élites urbanas y poder concejil en torno al control de los recursos hídricos». En García Fernández, Ernesto y Bonachía Hernando, Juan Antonio (eds.). Hacienda, mercado y poder al norte de la Corona de Castilla en el tránsito del Medievo a la Modernidad. Valladolid: Castilla Ediciones, 2015, pp. 501-527.

Rubio Martínez, Amparo. «Iglesia y hacienda regia: la participación de la iglesia compostelana en las rentas de la monarquía a fines del siglo XV». En García FernándeZ, Ernesto y Bonachía Hernando, Juan Antonio (eds.). Hacienda, mercado y poder al norte de la Corona de Castilla en el tránsito del Medievo a la Modernidad. Valladolid: Castilla Ediciones, 2015, pp. 325-353.

Rubio Martínez, Amparo. "Mercaderes y financieros en el arrendamiento de rentas reales en la Galicia del siglo Xv». En Bonachía Hernando, Juan Antonio y Carvajal de la Vega, David (eds.).Los negocios del hombre. Comercio y rentas en Castilla. Siglos XV y XVI. Valladolid: Castilla Ediciones, 2012, pp. 201-233.

Rubio Martínez, Amparo. Hacienda y gobierno de los Reyes Católicos en Galicia. Madrid: Universidad Complutense de Madrid, 2007.

Ruiz Albí, Irene. «Mujeres entre mercaderes. La presencia femenina en los protocolos notariales de la provincia de Valladolid en el tránsito del medievo a la modernidad». En García FernÁndeZ, Ernesto y Bonachía Hernando, Juan Antonio (eds.). Hacienda, mercado y poder al norte de la Corona de Castilla en el tránsito del Medievo a la Modernidad. Valladolid: Castilla Ediciones, 2015, pp. 39-67.

Solano FERnÁndez-SORdo, Álvaro. «Algunas cosas que son neçesarias para la buena governaçión de dicha villa e conçejo. Poder concejil, gobierno urbano y conflicto social en Villaviciosa a fines de la Edad Media». En García Fernández, Ernesto y Bonachía Hernando, Juan Antonio (eds.). Hacienda, mercado y poder al norte de la Corona de Castilla en el tránsito del Medievo a la Modernidad. Valladolid: Castilla Ediciones, 2015, pp. 469-499.

Vítores Casado, Imanol. «Poder, hacienda y mercados en la Cornisa Cantábrica a fines de la Edad Media: balances y perspectivas para una visión de conjunto». En Vítores CaSAdo, Imanol; Goicolea Julián, Francisco Javier;Angulo Morales, Alberto y Aragón Ruano, Álvaro (eds.). Hacienda, fiscalidad y agentes económicos en la Cornisa Cantábrica y su entorno (14501550). Nuevos textos para su estudio. Bilbao: Universidad del País Vasco, 2015, pp.31-55.

Vítores Casado, Imanol; Goicolea Julián, Francisco Javier;Angulo Morales, Alberto y AraGón Ruano, Álvaro (eds.). Hacienda, fiscalidad y agentes económicos en la Cornisa Cantábrica y su entorno (1450-1550). Nuevos textos para su estudio. Bilbao: Universidad del País Vasco, 2015. 
